\title{
Ettevõtluse paradokside tervikkäsitlus: „Entrepreneurship in theory and practice: Paradoxes in play"
}

\author{
Tõnis Mets ${ }^{\mathrm{a}}$ \\ ${ }^{a}$ Tartu Ülikooli majandusteaduskond
}

\begin{abstract}
Nielsen, S. L., Klyver, K., Evald, M. R., \& Bager, T. (2017). Entrepreneurship in theory and practice: Paradoxes in play (2nd rev. ed.). Cheltenham: Edward Elgar.
\end{abstract}

Teadmuspõhise Eesti majanduse mootoriks on uued alustavad ettevõtted, kes loovad või kasutavad uudset tehnoloogiat, st teadmuspõhine, sageli ka tehnoloogiaettevõtlus. Ettevõtlust distsipliinina iseloomustab asjaolu, et sageli eelneb ettevõtlusega seonduvate nähtuste teaduslikule uurimisele sotsiaalne praktika. Näiteks on leitud, et ettevõtlusprotsessi uuringud, eriti kui need põhinevad statistilistel andmetel, on maha jäänud pedagoogilisest praktikast (McMullen \& Dimov, 2013). Sellise tähelepanekuga on kaasnenud arusaam, et alustava ettevõtte (idufirma) nõustamisel konkreetses situatsioonis on vähe kasu üldistest statistilistest seaduspärasustest. Olulisem on ettevõtja ja tema firma tegelikkuse ning võimaluste tundmine ja ärakasutamine. Seda teavad hästi riskikapitalistid alustavatesse ettevõtetesse investeerimise kogemusest (Avnimelech, Schwartz, \& Bar-El, 2007): peale kümnete ja sadade äriideede põhjalikku sõelumist ning kriitilist analüüsi saavutab ainult väike osa alustavatest tehnoloogiaettevõtjatest edu.

Eesti kõrgharidussüsteem seisab valiku ees, kas toetada ettevõtluse kui kirjaoskuse omandamist, suunates üliõpilased, kes on oma eriala spetsialistidena veel küpsemata, otsima ideed ja arendama seda äritegevuseks, olgugi et see idee võib vahel olla naiivsevõitu, või arendada ettevõtlusteadmisi, mida saaks hilisemas elus hoopis küpsemate professionaalidena oma erialal rakendada. Esimene viis on tuntud kui ettevõtluse kaudu toimuv õpe, mis pakub ettevõtjaks olemise kogemust, seevastu teine on eelkõige ettevõtlusteadmiste kujundamine ehk distsipliinipõhine haridus. Viimase sihtrühm on valdkonna professionaalid, kes peaksid valdama nii kogemuslikku kui ka distsipliinipõhist arusaama ettevõtlusest. Tõenäoliselt võimaldatakse ülikoolis mõlemat tüüpi 
õpet edaspidigi. Seepärast on retsenseeritava raamatu ilmumine õigeaegne ka Eesti ettevõtlusalase mõtteviisi arengu seisukohalt. Peale sisuülevaate sisaldab raamatututvustus autorite seisukohtade hinnanguid senise ettevõtluspraktika ja -teooria arenduse kontekstis.

Kõik neli raamatu „Entrepreneurship in theory and practice: Paradoxes in play" autorit on Lõuna-Taani ülikoolist. Kuigi autoreid on mitu, on korduva läbikirjutamise tulemusena suudetud raamatus hoida ühtset stiili. Võrreldes esimese väljaandega on teise väljaande maht tänu neljale lisandunud peatükile oluliselt kasvanud. See asjaolu on võimaldanud tuua sisse uusi teemasid, nt disainmõtlemine, avaliku sektori ettevõtlus ja ettevõtluspoliitika. Ettevõtluse sisu avamiseks on autorid oma loomingule lisaks kasutanud juhtumikirjeldusi (kaasusi) mitmelt rahvusvaheliselt tuntud ettevõtlusuurijalt, sh W. B. Gartnerilt, S. Sarasvathylt, A. Fayollelt ja B. Honigilt. Kuigi sihtrühmana on nimetatud üliõpilasi, ületab ettevõtluse käsitlus esitatud paradokside keerukust arvestades tavapäraste õpikute piire. Seepärast võib raamatut vaadelda samuti kui ettevõtluse ja ettevõtlusõppe kontseptsioonide edasiarendust.

Raamatu viisteist peatükki on jaotatud nelja osasse. Kui sissejuhatav ja kokkuvõttev peatükk välja arvata, on igaüks pühendatud ühele paradoksile ettevõtluses. Nende paradokside sisuline arutelu on esitatud allpool. Peatükkide ülesehitus põhineb Kolbi õppimistsüklil: esmalt esitatakse praktikast pärinev narratiiv ja selle tõlgendus, seejärel tutvustatakse uut teooriat ja sellel põhinevat interpretatsiooni, millele järgneb teooria ja praktika sümbioosina saadud teadmusele tuginev kaasuse analüüs, millega omakorda juhatatakse sisse uus õppimistsükkel. Sel viisil imiteerib iga peatükk ühte võimalikku õppimistsüklit, keskendudes konkreetsele osale ettevõtlusprotsessist.

Esimeses osas „Sissejuhatus ettevõtlusesse“ ja ühtlasi raamatu esimeses peatükis „Mis on ettevõtlus?“ avatakse ettevõtluse ja ettevõtja mõiste neljas perspektiivis: 1) majandusteaduse, 2) sotsiaalpsühholoogia, 3) organisatsiooniteooria ja 4) ettevõtlusvõimaluse vaates. Majandusteaduslik käsitlus põhineb eelkõige Schumpeteril, kellele kuulub mõte ettevõtlusest kui „loovast hävitamisest", mille korral asendatakse vanad struktuurid uutega. Seevastu sotsiaalpsühholoogilise mõtteviisi järgi on ettevõtja teatavate (ettevõtjale omaste) isikuomaduste kandja. Organisatsiooniteooriaga seostub aga ettevõtja algatatav uue ettevõtte loomise ja käivitamise protsess. Ettevõtlusvõimaluse perspektiivist käsitletakse võimaluste äratundmist ja kasutamist. Seejuures kaks viimast vaadet konkureerivad üksteisega ja on omavahel tihedalt seotud. Sellest ülevaatest järeldub, et ettevõtjat ei iseloomusta mitte niivõrd see, milline on ta isikuomadustelt, vaid see, mida ta teeb ja kuidas ta tegutseb, st ettevõtlusprotsess. 
Teises peatükis otsitakse vastust küsimusele, kes on ettevõtja. Fookuses on esimene paradoks - küsimus, kas ettevõtjaks sünnitakse või saadakse. Esimene neist perspektiividest on levinud tihti tavaarusaamana, samuti viitab see kaasasündinud isikuomadustele, mis on omased nn geneetilisele ettevõtjale. Kuna isikuomadusi peetakse suhteliselt püsivaks, võiks arvata, et ettevõtjaks tõesti sünnitakse. Elu aga näitab, et sama inimene võib mingil perioodil olla ettevõtja ja järgmisel enam mitte. Globaalse ettevõtlusmonitooringu uuringust ilmnebki, et ettevõtjaks olemise valmidus sõltub vanusest. Samuti võib väita, et ettevõtjaks saamise eeldused arenevad koos individuaalse kognitiivse protsessiga oma äri loomisel, nagu selgub peatüki kaasuse kirjeldusest.

Teine osa „Ettevõtlusprotsess“ algab kolmanda peatükiga „Võimaluste teke“, kus keskendutakse ettevõtlusvõimaluse paradoksile ehk küsimusele, kas ärivõimalus eksisteerib objektiivselt ja ettevõtja avastab selle või ettevõtja hoopiski loob ärivõimaluse. Vastuse andmine nõuab ühtlasi idee ja võimaluse vahekorra mõtestamist. Schumpeterlik ettevõtja kui innovatsiooni looja erineb siin kirznerlikust ettevõtjast, kes kasutab olemasoleva info ära seal, kust ta teab olevat midagi puudu (info asümmeetria aspekt). Autorid osutavad kokkuvõtvalt, et innovatsiooniga viiakse turg tasakaalust välja, seevastu idee rakendusala laiendamisega tasakaalustatakse seda.

Peatükis „Võimaluste hindamine“, mis on järjekorras neljas, avatakse suhteliselt vähe uuritud külge ettevõtlusprotsessis. Ärijuhtimises kasutatavad nn instrumentaalsed analüütilised meetodid võimaldavad hinnata nõudlust turul, et selgitada ettevõtte ellujäämise võimalusi (nt tasuvusanalüüs). Ent võib juhtuda, et tarbijate heakskiidu saavutamiseks tuleb potentsiaalset võimalust turul veel tõestada, sest alles siis hakatakse selles nägema tegelikku võimalust. Selline probleemipüstitus võib osutuda iseäranis aktuaalseks tõeliselt uuenduslike äriideede ja toodete-teenuste korral. Nende valideerimiseks kasutatakse analüütiliste meetodite asemel tihti eksperimentaalseid meetodeid, sh sotsiaalset kommunikatsiooni. Üks valideerimise näide on toote prototüübi katsetamine potentsiaalsetel klientidel äri- ja tootearenduse varases faasis.

Viiendas peatükis püütakse leida vastust küsimusele, kas eesmärkide saavutamiseks ja ärivõimaluse elluviimiseks kasutada planeerimist või improvisatsiooni. Ettevõtlusvõimaluse elluviimine tähendab üldjuhul ettevõtlusprotsessi ja organisatsiooni loomist. Paljud aga äparduvad selles. Planeerimisel põhinevat organiseerimist vaadeldakse kui põhjuslikku (kausaalset, tihti ka lineaarset) protsessi. Seevastu improviseerimine võimaldab eesmärkide püstitust ja vahendite valikut kohandada paindlikult ettevõtja võimalustest, sotsiaalsest interaktsioonist ja keskkonna mõjuritest lähtudes. Sarasvathy (2008) kasutab sellise tagasisidestatud protsessi kirjeldamiseks ingliskeelset terminit effectuation, mille vasteks eesti keeles võiks olla tegestamine (tagasiside abil tegelikkuseks tegemine). 
Kuues peatükk „Alustav ettevõtlus“ on pühendatud küsimusele, kas ettevõtjaks hakatakse vajadusest sissetuleku ja töökoha järele või eneseteostust võimaldava keskkonna pakutavate võimaluste tõttu. Ettevõtja võib olla tööandjaks paljudele inimestele, kuid sageli on ta seda vaid iseendale. Samuti on võimalik olla ühteaegu palgatöötaja ja vabakutseline, jagades oma aega nende kahe hõivevormi vahel.

Kolmanda osa „Ettevõtlik sisu“ juhatab sisse peatükk „Ressursid“, kus esitatav paradoks seisneb ressursside kasutamises või nende avastamises ja tundmaõppimises. Esimesel juhul on ettevõtja seadnud sihiks olemasolevate ressursside tõhusama ja stabiilsema kasutuse, teisel juhul aga uute ressursside leidmise ja dünaamilise kontrolli.

Peatükis „Võrgustikud“ käsitletakse sotsiaalsete võrgustike rolli ettevõtja jaoks, otsides vastust küsimusele, kas need võrgustikud põhinevad eesmärgistatud ratsionaalsusel või on ladestunud (spontaanselt, kontrollimatult) suhtevõrgustikku varasemas elus. Kindla suunitlusega suhtevõrgustik luuakse konkreetsete eesmärkide saavutamiseks ja see lähtub üldjuhul vastastikusest kasust. Samas võib spontaanselt ühistel nn pehmetel väärtustel kujunenud võrgustik olla kasutaotluseta, kuid ettevõtja seisukohast mõjusam.

Üheksandas peatükis „Äriplaan“ püstitatakse küsimus, kas äriplaan on juhtimisinstrument või loovuse teejuht. Autorid jätkavad levinud diskussiooni äriplaani sisu, vajalikkuse ja kogemuse tähtsuse üle. Äri kavandamise vahendina käsitletakse samuti Osterwalderi ärimudeli kanvaad. Äriplaani kui juhtimisinstrumendi rollina nähakse võimalust püstitada reaalseid eesmärke, seada tulevikuplaane, vältida liialdusi, selgitada välja riskifaktorid, määrata kindlaks sihtrühm jne. Olulisimaks peetakse planeerimisprotsessi, mis võimaldab oma tegevuses plaaninäitajaid järgida. Äriplaani kui paindlikku ja pidevalt uuenevat dokumenti käsitatakse vahendina, mis aitab ettenägematuid suundumusi süsteemselt mõtestada ja nendega toime tulla. Loovusele jäetakse ruumi, kui ei püüta ennustada ja planeerida ennustamatut, vaid lahendatakse uusi olukordi loovalt.

Peatükis „Disainmõtlemine“ vastandatakse ettevõtlik ja disainmõtlemine. Disainmõtlemise komponentidena nähakse mineviku- ja olevikusituatsiooni ning tulevikuvõimaluste teadvustamist, vastates järgmistele küsimustele: Mis on?, Mis oleks, kui ...?, Mis huvitab?, Mis toimib?. Disainmõtlemisega seostatakse sotsiaalkonstruktivistlikku lähenemisviisi ja mitmesuguseid turu tagasisidel põhinevaid tootearendusideid. Tuginedes Shane'i ja Venkataramani (2000) klassikalisele definitsioonile, rõhutavad autorid ettevõtliku mõtlemise puhul võimet avastada ja kasutada ettevõtlusvõimalusi minevikust ja tänapäevast. Sel viisil vastandub ettevõtlik mõtlemine disainmõtlemisele, mis peaks omaduste loetellu lisama tulevikuvaate, iteratiivse protsessi ja orienteerituse üldistele väärtustele. 
Neljas osa „Ettevõtlik kontekst“ algab peatükiga „Siseettevõtlus“, kus käsitletakse olemasolevate organisatsioonide ettevõtliku tegutsemise alusena alt üles ja ülevalt alla aktiivsust. Selles protsessis on tähtis koht innovatsioonil, mis Skandinaavia maade firmade näitel on võimaldanud olla edukas, hoolimata sellest, et globaalse ettevõtlusmonitooringu järgi on ettevõtlusaktiivsuse näitajad suhteliselt tagasihoidlikud. Peamise probleemina nähakse raskusi mõlema käsitlusviisi (alt üles ja ülevalt alla) tasakaalustatud rakendamisel suuremas organisatsioonis.

Kaheteistkümnendas peatükis keskenduvad autorid küsimusele, kas sotsiaalne ettevõtlus suundub äri või parema maailma poole ning kuidas saaks neid kaht sihti ühitada. Arutelu keskmes on vajaduspõhise ja võimalusest tuleneva ettevõtluse klassikaline dilemma. Samuti pööravad autorid selles peatükis eritähelepanu innovatsioonile sotsiaalsetes valdkondades, võttes teemaks, kuidas luuakse töökohti ja suurendatakse kogukondade sidusust.

Peatükis „Avalik(u sektori) ettevõtlus“ esitatakse paradoksina küsimus, kas avaliku sektori ettevõtlus on oma olemuselt suletud või avatud. Kuigi peatükki illustreeriv kaasus on seotud nii avaliku teenuse (meditsiini)sektori kui ka eraettevõtlusega, vaadeldakse avaliku sektori ettevõtlust laiemas tähenduses, sh poliitilisel tasandil, mida esindavad (valitud) poliitikud, täideviival tasandil, mida esindavad juhid ja avalikku teenust osutavad ametnikud, ning arvamusliidrite poliitika tasandil. Seejuures kujundab avalikku sektorit kaks suunda: toimivat turupõhist ratsionaalsust taotlev uus haldusjuhtimine (new public management, NPM) ja võrgustikuorientatsiooniga uus avalik haldus (new public governance, NPG). Kui suletud süsteemis puudub eri sektorite vahel koostöö või see on minimaalne, siis tänapäevase avaliku sektori ettevõtlust iseloomustab koostöö avaliku, mittetulundus- ja ärisektori vahel.

Peatükis „Ettevõtluspoliitika“ on seatud valitsus (laiemalt ühiskond) järgmise paradoksi ette: kas valida eesmärgiks jõukus või heaolu. Ettevõtluspoliitika ülesandena nähakse indiviidide ja organisatsioonide tarbeks struktuurse ja majandusliku raamistiku (sh ettevõtluse ökosüsteemi - T. M.) loomist, mis esindab makroperspektiivi. Need kaks tahku ühtaegu konkureerivad omavahel ja täiendavad teineteist. Ettevõtluspoliitikaga soovitakse vähendada suures osas kasvule orienteeritud innovaatiliste iduettevõtete (start-up-firmade) turutõrkeid. Turutõrgeteks on nii ettevõtlus- kui ka tehnoloogiateadmiste vähesus, aga ka näiteks soolised ja regionaalsed tegurid ning potentsiaalse ettevõtja kuuluvuse ja päritoluga (vähemusrühmad, immigrandid) seotud asjaolud. Poliitika abil püütakse samuti ületada regulatiivseid takistusi firma registreerimisel ja ressursside hankimisel, sh rahastamisel.

Kokkuvõtvas, viieteistkümnendas peatükis tehakse tagasivaade käsitletud paradoksidele, lähtudes objektiivsest ja subjektiivsest vaatenurgast. Esimene 
neist esindab ettevõtluse planeeritavat tahku, teine aga paindlikku, loovat ja õppivat lähenemist ettevõtlusele kui protsessile. Tervikuna võib neid kahte tahku pidada ettevõtluse metaparadoksiks. Kuigi igal ettevõtjal, aga ka õppuril kulgeb see protsess erinevalt, moodustub lõppkokkuvõttes tulevikku kujundav ettevõtluse teekond, mille algusesse raamat lugeja juhatabki.

Ettevõtluse kui distsipliini sisu avamise seisukohalt võib retsenseeritavat raamatut pidada heaks sissejuhatuseks valdkonda. Ettevõtluse temaatiline pool on kaetud ulatuses, mis ei kajastu paljudes varasemates õpikutes (vt nt Baron \& Shane, 2008; Bygrave \& Zacharakis, 2011) ja kokkuvõtlikes raamatutes (Davidsson, 2016). Samas ei asenda raamat nimetatud väljaandeid, mida võib üldjoontes käsitleda praktilise käsiraamatuna või teoreetilise ülevaatena distsipliinist. Paradokside avamine viisil, nagu autorid on seda teinud, sunnib lugejat, sõltumata varasemast ettevalmistusest, läbi mõtlema ettevõtluse olemuse ja põhiteemad. Kasutatud kaasuste kirjeldused toetavad hästi probleemipüstitust. See tuletab meelde, et ettevõtlusprotsess on igal konkreetsel juhul ainukordne, aga samas õpetlik, avades ettevõtja ees seisvaid valikuid. Nii saab iga juhtumi siduda konkreetse teoreetilise suunaga. Paradokside poolt- ja vastuargumendid ning nende sümbioos kaasuste analüüsil juhatavad hästi sisse ettevõtluse teoreetilise käsitluse. Sellisena on raamat väärtuslik nii üliõpilasele kui ka valdkonna professionaalile, kelleks magistriõppe läbinu peaks kujunema.

Raamatu puudusi tuleks otsida nendest aspektidest, mida autorid üritavad esitada teatava üldistusena paradokside kohta. Tekib küsimus, kuivõrd on need kooskõlas senise teooria ja praktikaga ning mis on neis seisukohtades uut ja mis ei vasta võib-olla päriselt senisele praktikale. Peatükkides sisalduvate kirjandusviidete hulka arvestades võib öelda, et autorid on paradokside avamisel tuginenud paljudele varasematele uurimustele. Samas sunnib see lugejat küsima, kas seejuures on lähtutud paradoksi sisule täpselt vastavatest allikatest või kas tegu on tõeliste paradoksidega. Küsimus, kas ettevõtjaks sünnitakse või kasvatakse, on ettevõtluse teoorias ja pedagoogikas traditsiooniline. Samuti on küllaltki palju uuritud ettevõtlusvõimaluse olemust ehk seda, kas see võimalus eksisteerib niisama või loob selle ettevõtja. Hoopis vähem on uuritud võimaluse hindamist, mis seostub samuti eesmärkide saavutamise viisiga, seades vastakuti planeerimise ja improvisatsiooni (kolmas ja neljas paradoks). Siinkohal peab nentima, et raamatu märksõnade hulgast puuduvad säästlik idufirma (lean start-up) ja minimaalne võimalik toode (minimum viable product), mis märgivad metoodilist lähenemisviisi, mida ettevõtjad kasutavad sageli oma innovaatilise toote prototüübi (idee) testimiseks/hindamiseks enne toote füüsilist valmimist (vt Blank, 2010; Ries, 2011). See ennekõike ettevõtluspraktika aspekt oleks kindlasti täiendanud paradokside käsitlust raamatus. 
Eritähelepanu väärib ettevõtliku ja disainmõtlemise vastandus. Tundub, et lähtumine Shane’i ja Venkataramani (2000) klassikalisest artiklist ettevõtlusuuringute kohta pole päris põhjendatud - viidatava artikli eesmärk ei ole kindlaks määrata ettevõtliku mõtlemise piire. Seepärast tundub autorite esiletoodud ettevõtliku ja disainmõtlemise vastuolu kunstlik. Pealegi, juba ammu enne aastat 2000 oli visiooni kujundamine juhtimise, sh äriplaani kui ühe ettevõtluse instrumendi lahutamatu osa. Ettevõtja tulevikuvisiooni loomine äriplaani osana on oma olemuselt kahtlemata disainmõtlemise tulemus.

Raamatu märksõnade hulgast puudub ettevõtluse ökosüsteemi mõiste, kuigi selle elemente käsitletakse ettevõtluspoliitikaga seoses. Siinkirjutaja arvates jääb piiratuks ka poliitilise ettevõtluse käsitlus, kui võtta arvesse, et poliitikute otsustest sõltuvad paljud ettevõtluse ökosüsteemi kujundavad otsused. Eesti senist arengutki võib vaadelda kui poliitilise ettevõtluse tulemust (Mets, 2017). Poliitilise ettevõtluse lühi- ja pikaajaline perspektiiv on kindlasti üks ettevõtluse paradokse, mis väärib uurimist.

Kokkuvõtteks saab märkida, et käsitluse mõningasest piiratusest hoolimata on autorid suutnud avada ettevõtluses sisalduvaid paradokse. Raamat mitte üksnes ei paku teoreetilist vaatenurka distsipliinile, vaid ka suunab lugejat kriitiliselt analüüsima ettevõtluse pakutavaid võimalusi ning avardab kaasuste ja paradokside kaudu ettevõtja mõtteviisi, soodustades selle praktilist rakendamist ettevõtlusprotsessis. Sellisena on raamat väärtuslik nii teadusliku distsipliinikeskse käsitluse kui ka pedagoogilise praktika seisukohalt.

\section{Kasutatud kirjandus}

Avnimelech, G., Schwartz, D., \& Bar-El, R. (2007). Entrepreneurial high-tech cluster development: Israel's experience with venture capital and technological incubators. European Planning Studies, 15(9), 1181-1198.

https://doi.org/10.1080/09654310701529078

Baron, R. A., \& Shane, S. A. (2008). Entrepreneurship: A process perspective (2nd ed.). Cincinnati: Thomson South-Western.

Blank, S. (2010). Perfection by subtraction - The minimum feature set. Retrieved from https://steveblank.com/2010/03/04/perfection-by-subtraction-the-minimumfeature-set/.

Bygrave, W. D., \& Zacharakis, A. (Eds.) (2011). The portable MBA in entrepreneurship (4th ed.). John Wiley \& Sons.

Davidsson, P. (2016). Researching entrepreneurship: Conceptualization and design (2nd ed.). New York: Springer.

McMullen, J. S., \& Dimov, D. (2013). Time and the entrepreneurial journey: The problems and promise of studying entrepreneurship as a process. Journal of Management Studies, 50(8), 1481-1512. https://doi.org/10.1111/joms.12049 
Mets, T. (2017). Entrepreneurship in Estonia: Combination of political and entrepreneurial agenda. In A. Sauka \& A. Chepurenko (Eds.), Diverging paths: Entrepreneurship in CEE and CIS (pp. 115-133). New York: Springer International. https://doi.org/10.1007/978-3-319-57342-7_7

Ries, E. (2011). The lean startup: How today's entrepreneurs use continuous innovation to create radically successful businesses. New York: Crown Business.

Sarasvathy, S. D. (2008). Effectuation: Elements of entrepreneurial expertise. Cheltenham: Edward Elgar Publishing. https://doi.org/10.4337/9781848440197

Shane, S., \& Venkataraman, S. (2000). The promise of entrepreneurship as a field of research. Academy of Management Review, 25(1), 217-226.

https://doi.org/10.5465/amr.2000.2791611 